\title{
Improving Power Harvesting Ability of Variable Speed Wind Turbine Using Intelligent Soft Computing Technique
}

\author{
Endalew Ayenew Haile \\ Center of Excellence for Sustainable \\ Energy, Addis Ababa \\ Science and Technology University \\ Addis Ababa, Ethiopia \\ endalewayenew@gmail.com.et
}

\author{
Getachew Biru Worku \\ Department of Electrical Power and \\ Control Engineering \\ Science and Technology University \\ Adama, Ethiopia \\ gbiru@yahoo.co.uk
}

\author{
Asrat Mulatu Beyene \\ Center of Excellence for Sustainable \\ Energy, Addis Ababa \\ Science and Technology University \\ Addis Ababa, Ethiopia \\ asrat.mulatu@astu.edu.et
}

\author{
Milkias Berhanu Tuka \\ Department of Electrical Power and Control Engineering \\ School of Electrical Engineering and Computing Adama \\ Adama, Ethiopia \\ mil_ber2000@astu.edu.et
}

\begin{abstract}
This paper presents a study carried out on maximizing energy harvesting of wind turbines. One way of improving the output power of the wind turbines is by optimizing the power conversion coefficient. The power conversion coefficient factor is expressed as a function of the wind turbine blade tip speed ratio and the turbine blade pitch angle. Optimization of the wind turbine generator output power is done by considering the effects of variations of wind speed, blade tip speed ratio, and pitch angle. An intelligent soft computing technique known as an adaptive neuro-fuzzy inference system (ANFIS) with a fuzzy logic controller for blade pitch actuator was applied to optimize the generator output power. The simulation result showed that the power conversion coefficient of 0.513 is achieved. The study was verified by using real-time wind speed data of Adama II wind farm in Ethiopia and specifications of the Gamesa G80 horizontal axis wind turbine generator unit by MATLAB software. Accordingly, a promising and satisfying improvement in power harvesting capacity is obtained. The output power of this generator is improved by $9.47 \%$ which is by far better result as compared to the existing literature.
\end{abstract}

Keywords—optimization tool, pitch angle, tip speed ratio, wind energy conversion coefficient

\section{INTRODUCTION}

The wind is a potential resource of renewable energy with a global contribution of $74 \mathrm{GW}, 198 \mathrm{GW}, 487 \mathrm{GW}, 540 \mathrm{GW}$, $591 \mathrm{GW}$, and $651 \mathrm{GW}$ in 2006, 2010, 2016, 2017, 2018, and 2019, respectively [1]. An inclusive knowledge of the wind features is very significant for the planning and development of wind power generation plants. Wind turbines are categorized into fixed speed types (FST) and variable speed types (VST). The VST turbines can extract more power [2, 3, 4] and rotor speed must be modified based on wind velocity [5]. Pitching and active-stall mechanisms are applied to control the turbine blade pitch angle $(\beta)$. In the energy conversion process from wind to mechanical form, maximizing the energy harvesting ability of wind turbines is a very crucial parameter. The energy to be extracted is linked to the cube of the wind speed; hence a change of $10 \%$ in wind speed leads to a $33.1 \%$ increase or $27.1 \%$ decrease in energy. When wind speed is below the nominal value, the generator torque control technique can be used to optimize the energy conversion coefficient $\left(\mathrm{C}_{\mathrm{p}}\right)$ and hence better power can be captured. In this case, the blade pitch angle is maintained near zero degrees. When the wind speed is above the nominal value, blade actuator control is used to limit $C_{p}$ and hence the captured power can be regulated to the nominal value of a turbine which avoids mechanical damage to the system. In any of the two of these cases, the power harvesting capacity of the wind turbines is directly influenced by $\mathrm{C}_{\mathrm{p}}$.

The main need for enhanced value of $\mathrm{C}_{\mathrm{p}}$ is to upsurge the wind turbine productivity and hence reduce the cost of energy production. For this purpose, different algorithms of maximum power point tracking (MPPT) for wind energy conversion systems (WECS) using wind turbines were discussed in the literature. For example, [6, 7, 8] depicted different algorithms of the MPPT of the wind turbine and, their application ranges, strengths, and limitations. To mention some, tip speed ratio control, power signal feedback control, optimal torque control, perturb and observe, hill climb search, hybrid of MPPT algorithms, and artificial intelligence were discussed. Improved MPPT-curve method with Lyapunov function based PI control was presented by [9]. According to this study, the optimal $C_{p}$ value of 0.472 was achieved. Another study [10] on MPPT of a permanent magnet synchronous generator (PMSG) based on WECS was carried out by employing conventional optimum torque control with a toque error feed-forward algorithm and the optimal $\mathrm{C}_{\mathrm{p}}$ of 0.423 was realized. According to the researches $[11,12]$, the maximum achievable value of $C_{p}$ ranges between 0.2 and 0.4 for wind turbines with three or more blades. Neuro-fuzzy methods were applied to estimate the power conversion coefficient for wind turbines and the maximum estimated power coefficient was 0.352 [13] which is not the optimal value. In [14], an optimal $\mathrm{C}_{\mathrm{p}}$ of 0.5 is achieved by using a radial base function neural network along with optimal torque control by employing MPPT for double fed induction generator (DFIG) based WECS. The simulation result of the study on the optimized pathway aero-generator modelling and control of wind turbine driven by PMSG shows a power conversion coefficient of 0.43 [[15]. For three-blade wind turbines, [16] presented an optimal value of $C_{p}$ equal to 0.47 . As per [17], a value of $2.36 \%$ improvement in power is obtained by using the maximum extraction technique with 
power optimization and control. The main limitation in their work is the consideration of a short time simulation period. The paper [18] tried to optimize power extraction from the wind by implementing robust estimation and Lyapunov extremum seeking control scheme. It was reported about $47.25 \%$ extraction of power from the wind. As per [19], optimally designed wind turbines with two or three blades can have $\mathrm{C}_{\mathrm{p}}$ above 0.4 . These reviews showed the power harvested from the wind by a turbine is less due to low $C_{p}$.

This study aims at maximizing the power harvesting ability of variable speed variable pitch angle wind turbines by optimizing $\mathrm{C}_{\mathrm{p}}$ with the use of an intelligent soft computing mechanism called an adaptive neuron-fuzzy inference system (ANFIS). It is an attempt to associate $C_{p}$ to tip speed ratio $(\lambda)$ and blade pitch angle $(\beta)$ by controlling the wind turbine blade pitch actuator. Optimal power can be captured only under an optimal value of $C_{p}$ at optimal values of $\lambda$ and $\beta$. Optimal design of the wind turbine blade aerofoil, pitch drive and control mechanism can be used to achieve the optimal values of $\lambda$ and $\beta$.

A literature study suggests that Fuzzy logic based proportional integral and derivative (PID) were employed for wind turbine blade pitch angle control for optimization of $\mathrm{Cp}$ and power regulation [24, 25]. ANFIS was used for the assessment of wind speed [20]. ANFIS is the most powerful network [21] and is used in different applications [22, 23] due to its ability to automate, learn, and update. It overcomes limitations in neural and fuzzy logic networks when they are used individually.

From a practical perspective, the major contributions can be summarized as follows:

- A new method to maximize energy harvesting of a wind turbine is investigated.

- Wind turbine generator output power optimization is carried out by optimizing $C_{p}$ through turbine blade pitch actuator control by avoiding the use of a nonlinear complex dynamic model of turbine and generator.

- Only four physical parameters (wind speed, turbine rotor speed, blade pitch angle, and generator output power) are to be measured and supplied to the two controllers.

- The method simplifies the optimization problem computationally. It simplified the complex control mechanism for the optimization of the output power of WECS due to uncertain wind speed.

Next, the Materials and Method, Results and Discussion, and Conclusion of the research are presented as follows.

\section{METHODS}

Real-time wind speed data were collected at 10 meters above ground for the complete year of 2019 at the ADAMAII wind farm site in Adama, Ethiopia. This site is geographically located at the latitude of $8^{\circ} 18^{\prime} 35.5^{\prime \prime} \mathrm{N}$, the longitude of the $38^{\circ} 53^{\prime} 4.2^{\prime \prime} \mathrm{E}$ and elevation of $1712 \mathrm{~m}$ above sea level in Ethiopia about $95 \mathrm{~km}$ far away to the southeast of Addis Ababa. The picture of the Adama wind farm site is shown in Fig. 1. The data is collected using the WICOM-32 data logger and is logged every 10 minutes. Every day, the
WICOM-32 data logger stores 144 samples. Each sample contains mean wind speed, maximum wind speed, minimum wind speed and standard deviation in $\mathrm{m} / \mathrm{s}$ and wind direction in degree with one sample measurement value of 13.3, 14.9, $11.2,0.6,74$, respectively. The analysis of this data and the optimization were done by using MATLAB software. From this data, the wind speed is presented in Fig. 2 and the direction of the wind in Fig. 3. The wind rose diagram depicts most of the wind speed is above $5 \mathrm{~m} / \mathrm{s}$ and flows toward the east northeast (ENE) direction. The wind speed between 3 to $4 \mathrm{~m} / \mathrm{s}$ is also in the ENE direction as is indicated in Fig. 3 for the mentioned year. This data is extrapolated to the hub height of the Gamesa G80 off-grid wind turbine.

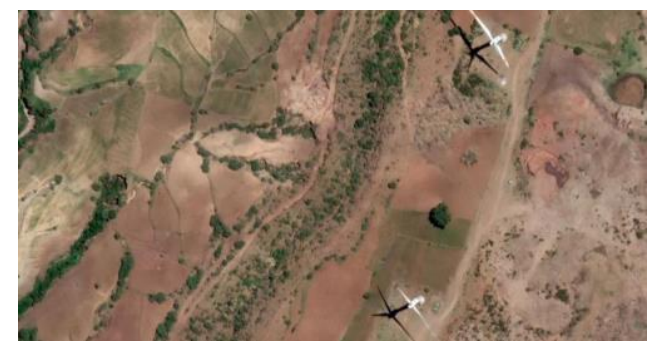

Fig. 1. The Adama-II wind farm site picture

To illustrate the significance of power conversion coefficient in the conversion of the kinetic energy of the wind into mechanical energy, the model of the wind power $\left(\mathrm{P}_{\mathrm{a}}\right)$ in watt for the horizontal axis wind turbine with a blade radius of $\mathrm{R}$ forms a swept area $\left(\mathrm{A}=\pi \mathrm{R}^{2}\right)$ in $\mathrm{m}^{2}$ and is presented below as a function of wind speed $\left(V_{a}\right)$ in $\mathrm{m} / \mathrm{s}$, air compactness $(\rho)$ in $\mathrm{kg} / \mathrm{m}^{3}[3,4]$.

$$
P_{a}=0.5 \rho \pi R^{2} V_{a}^{3}
$$

The turbine rotor harvests a fraction of the power available in the wind. The ratio of rotor output power $\left(\mathrm{P}_{\mathrm{g}}\right)$ in watt to $\mathrm{P}_{\mathrm{a}}$ is called a power conversion coefficient expressed as

$$
\mathrm{C}_{\mathrm{p}}=\frac{\mathrm{P}_{\mathrm{g}}}{0.5 \pi \rho \mathrm{R}^{2} \mathrm{~V}_{\mathrm{a}}^{3}}
$$

As discussed in part $1, \mathrm{C}_{\mathrm{p}}$ is related and/or adjusted to/by $\beta$ and $\lambda$ [19]. For variable speed pitch regulated horizontal axis wind turbine, mathematically $\mathrm{C}_{\mathrm{p}}$ was approximated by [27].

$$
\begin{aligned}
& \mathrm{C}_{\mathrm{p}}(\lambda, \beta)=0.73\left(\left(\frac{151}{\lambda_{\mathrm{j}}}\right)-0.58 \beta-0.002 \beta^{2.14}\right) \exp \left(-\frac{18.4}{\lambda_{\mathrm{j}}}\right) \\
& \frac{1}{\lambda_{\mathrm{j}}}=\frac{1}{\lambda+0.02 \beta}-\frac{0.03}{1+\beta^{3}}
\end{aligned}
$$

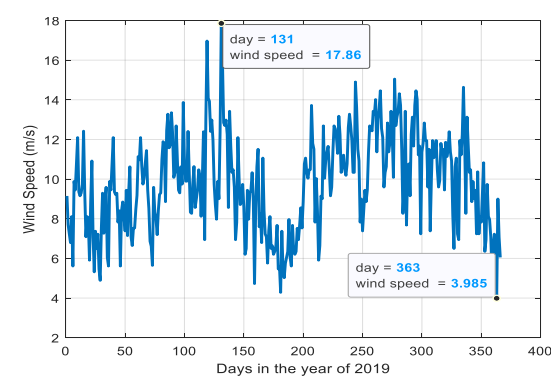

Fig. 2. Real-time wind speed for the complete year 2019 (Adama Ethiopia) 


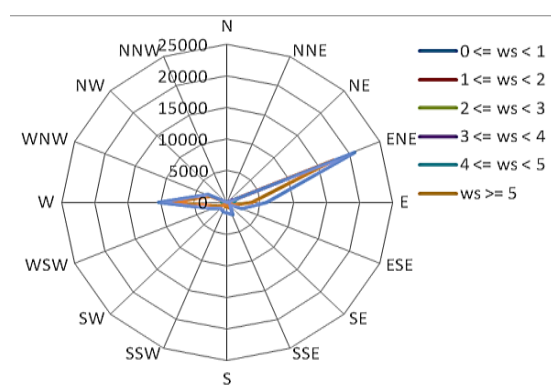

Fig. 3. The wind rose diagram for the complete year 2019

$$
\begin{aligned}
& \lambda=\frac{\omega R}{V_{a}} \\
& \beta=\arctan \left(\frac{2 R}{3 r \lambda}\right)-\alpha_{a}=\frac{2}{3} \arctan \left(\frac{V_{a}}{\omega r}\right)-\alpha_{a}
\end{aligned}
$$

Where $\omega$ is the rotor angular speed of the wind turbine $(\mathrm{rad} / \mathrm{s}), \alpha_{a}$ is the angle of attack of the blade and ranges from $5^{0}$ to $10^{0}$ to provide maximum air attach to the blade [28], and $r$ is the fraction of the blade length-R. For a VST wind turbine, tip speed ratio $(\lambda)$ is the ratio of the blade tip peripheral speed to the wind speed; and $\beta$ is a rotor blade pitch angle. The primary objective of using ANFIS is to maximize wind power to mechanical power conversion efficiency $C_{p}(\lambda, \beta)$ of a variable speed horizontal axis wind turbine. Rearranging equation (2), the harvested power by the turbine is

$$
\mathrm{P}_{\mathrm{t}}=0.5 \rho \pi \mathrm{R}^{2} \mathrm{~V}_{\mathrm{a}}^{3} \mathrm{C}_{\mathrm{p}}(\lambda, \beta)
$$

As well known, pitch angle control is not required for the optimization of $C_{p}(\lambda, \beta)$ in the case of the wind speed below the nominal speed. Hence, the value of the $\beta$ in equation (3) is approximately set to near zero degrees and according to the wind speed condition, it could be adjusted. In this case, $\mathrm{C}_{\mathrm{p}}(\lambda$, $\beta$ ) depends only on the tip speed ratio $(\lambda)$. To capture maximum power, the turbine should operate at its highest aerodynamic power conversion capacity i.e. $C_{p}(\lambda, \beta)$ is set to $\mathrm{C}_{\mathrm{p}-\mathrm{max}}$ at certain pitch angles and optimal tip speed ratio $\left(\lambda_{\text {opt }}\right)$ which is determined using ANFIS. In equation (6) the maximum aerodynamic available power $\left(\mathrm{P}_{\mathrm{a}-\max }\right), \mathrm{V}_{\mathrm{a}}=\omega \mathrm{R} / \lambda_{\mathrm{opt}}$, and $\mathrm{C}_{\mathrm{p}-\mathrm{max}}$ are related as

$$
\mathrm{P}_{\mathrm{a}-\max }=0.5 \rho \pi \mathrm{R}^{2} \mathrm{C}_{\mathrm{p}-\max } \frac{\omega^{3}}{\lambda_{\text {opt }}{ }^{3}}
$$

In Eq. (7), the resulting power is maximum for $\mathrm{C}_{\mathrm{p}-\max }$ maximum. According to Betz's limit, theoretically, the maximum value of the power conversion coefficient is 0.593 $[27,29]$. From equation (3), the maximum value of $C_{p}$ is 0.41 at $\beta$ equals to $0^{\circ}$ and $\lambda$ equal to 8 as shown in Fig. 4. Generally, wind turbines convert only about $30 \%$ to $35 \%$ of the available wind energy into electrical energy due to mechanical and electrical losses in addition to aerodynamic or blade losses [30].

As it is depicted in equation (6), the output power of a specific wind turbine is related to a fixed rotor radius, varying wind speed, air density, and power conversion coefficient. The power conversion coefficient is indicated in equations (3) and (4). It is governed by the two varying parameters, tip speed ratio and pitch angle, of the wind turbine blade. These two parameters are presented in mathematical equations (5a) and (5b). In these two equations, the combined varying effect of wind speed and wind turbine rotor speed is visualized in the tip speed ratio. Moreover, the combined impact of the four variables, wind speed, rotor speed, blade elemental radius (r), and blade angle of attack, is envisaged in the pitch angle of the blade. Therefore, all of these input variables affect the power conversion coefficient through tip speed ratio and pitch angle of the wind turbine blade. That is the main reason for the selection of the three variables, two inputs and one output, are considered in the optimization of the output power of the wind turbine. ANFIS structure based on these three variables provides improved value of power conversion coefficient of the wind turbine.

ANFIS is employed to maximize power extraction from the wind by the wind turbines. The structure of ANFIS is a hybrid of artificial neural network (ANN) and the Fuzzy inference system (FIS). ANN and fuzzy-logic models have their strengths and weakness, the ANFIS hybridized the strengths of these techniques [31, 32, 33]. The ANFIS is an adaptive network, it comprises features of ANN and FIS and removes some of their weakness [34]. The ANFIS is proficient in the treatment of complicated and nonlinear problems [35]. Thus, instead of individually using ANN or fuzzy-logic models, the ANFIS is more suitable to handle the complex problem [36].

Optimization of a parameter by employing ANFIS with a small number of inputs reduces the learning complexity in the membership functions of inputs. That is, the advantages of applying a small number of input-output data pairs to ANFIS is to minimize the number of neurons in the structure of ANFIS itself. Therefore, this simplifies the parameters training complexity.

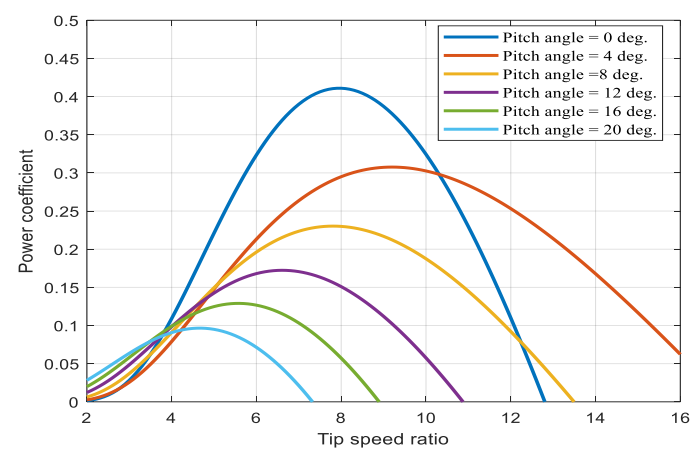

Fig. 4. Power conversion coefficient as a function of tip speed ratio and pitch angle

\section{A. Proposed Optimization Scheme}

The proposed real-time soft computing intelligent system to optimize power harvesting ability of wind turbine is revealed in Fig. 5, which depicts instantaneous wind speed data that is measured by an anemometer from the environment; and turbine rotor speed, blade pitch angle, and generator output power, which are measured from physical plant. Its output is given to the pitch angle actuator controller for comparison with the set or nominal value. In case the actual wind speed is far from the nominal value, the error between generator output power $\left(P_{g}=\eta_{g} \eta_{g b} P_{t}\right.$; for $\eta_{g}$ and $\eta_{g b}$ are the efficiency of generator and gearbox respectively) and generator nominal $\left(\mathrm{P}_{\mathrm{ref}}\right)$ power will be non-zero. Based on this error, the turbine blade will be pitched by the actuator, and hence $\beta$ and rotor speed are optimally regulated. The $\beta$ and $\lambda$ 
from the wind turbine are inputs to the ANFIS model (denoted by functional blocks of Feed-Forward Neural Network of five levels) to optimize $C_{p}$. The motivation of presenting the ANFIS for mapping $C_{p}$ to $\lambda$ and $\beta$ is to maximize wind turbine output power. The main advantage of such an approach is to simplify a complex control mechanism to optimize the output power of WECS in uncertain wind speed. Among the several types of FIS techniques (Tsukamoto, Mamdani, and TakagiSugeno), the Sugeno type FIS is selected for this study and hence used. The fuzzy IF-THEN rules in FIS and two inputs to the Sugeno model are related as

$$
\text { If } \lambda \in \lambda_{\mathrm{i}} \text { and } \beta \varepsilon \beta_{\mathrm{i}} \text { then } \mathrm{g}_{\mathrm{i}}=\mathrm{a}_{\mathrm{i}} * \lambda+\mathrm{b}_{\mathrm{i}}^{*} \beta+\mathrm{c}_{\mathrm{i}}
$$

The consequent factors $a_{i}, b_{i}$, and $c_{i}$ are allocated throughout the ANFIS's training. The numbers of inference rules are $i=1,2 ; \lambda_{i}$ and $\beta_{i}$ are the membership functions (MFs) of inputs in the premises; $\lambda$ and $\beta$ are measurable variables of the wind turbine and $\mathrm{g}_{\mathrm{i}}$ is the fuzzy set. In Fig. 5, fuzzification of inputs crisps is carried by neurons or nodes within level 1 which are self-update nodes of triangular-shaped MFs described by equations (9a) and (9b) and characterized by the degrees $\mu_{\lambda_{i}}(\lambda)$ and $\mu_{\beta_{i}}(\beta)$, as in Table 1 and Fig. 6 for $\mathrm{j}=1$, $2 \ldots .5$ is MFs in the specific rule.

$$
\begin{aligned}
& \mu_{\lambda_{i}}(\lambda)=\max \left(\min \left(\frac{\lambda-\chi_{i j}}{\delta_{i j}-\chi_{i j}}, \frac{\gamma_{i j}-\lambda}{\gamma_{i j}-\chi_{i j}}\right), 0\right) \\
& \mu_{\beta_{i}}(\beta)=\max \left(\min \left(\frac{\beta-p_{i j}}{q_{i j}-p_{i j}}, \frac{\xi_{i j}-\beta}{\xi_{i j}-q_{i j}}\right), 0\right)
\end{aligned}
$$

Where $\Theta=\left[\chi_{i j}, \delta_{i j}, \gamma_{i j}, p_{i j}, \xi_{i j}, q_{i j}\right]$ are the fuzzy membership premise parameters to be optimally updated for nodes in level 1 for $\mathrm{i}=1,2$. All nodes in level 2 were nonadaptive that evaluate weights of each MFs multiplying (i.e. fuzzy AND or product execution) the inward signals from the $1^{\text {st }}$ level and propel the rule's firing potency.

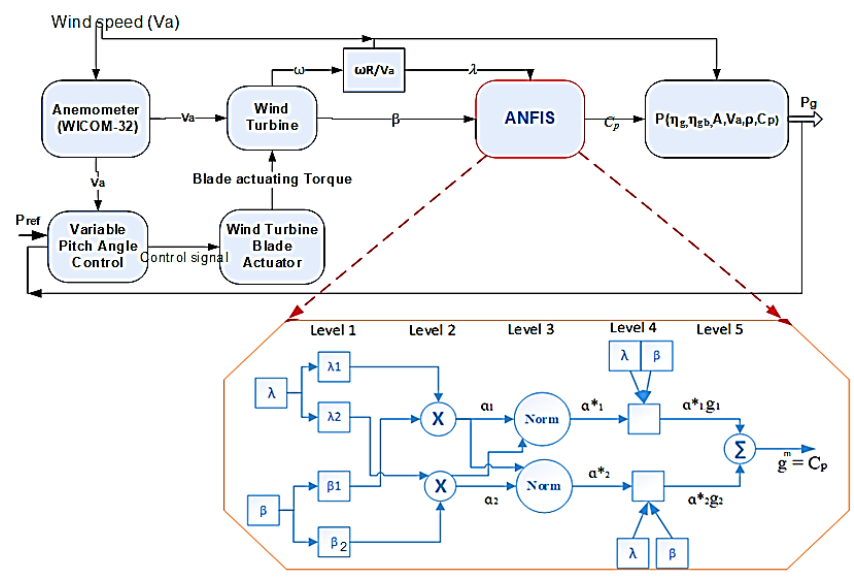

Fig. 5. Proposed system configuration to maximize poer harvesting ability of wind turbine

$$
a_{i}=\mu_{\lambda_{i}}(\lambda) * \mu_{\beta_{i}}(\beta)=\left\{\begin{array}{l}
\left(\frac{\lambda-\chi_{i j}}{\delta_{i j}-\chi_{i j}}\right) *\left(\frac{\beta-p_{i j}}{q_{i j}-p_{i j}}\right) ; \text { for } \chi_{i j} \leq \lambda \leq \delta_{i j} ; p_{i j} \leq \beta \leq q_{i j} \\
\left(\frac{\gamma_{i j}-\lambda}{\gamma_{i j}-\delta_{i j}}\right) *\left(\frac{\xi_{i j}-\beta}{\xi_{i j}-q_{i j}}\right) ; \text { for } \delta_{i j} \leq \lambda \leq \gamma_{i j} ; q_{i j} \leq \beta \leq \xi_{i j}
\end{array}\right.
$$

Every node in level 3 is also non-adaptive which executes the required matching of the fuzzy rules and working out on their activation. They also calculate normalized weights and the fraction of the rule's firing potency to the total of the whole rules' firing potencies as in equation (11).

$$
a_{i}^{*}=a_{i} / \sum_{i=1}^{R=2} a_{i}
$$

The inference of rules of the outputs is de-fuzzified by level 4. Every node in level 4 is self-updated with the function

$$
a_{i}^{*}{ }^{*} g_{i}=a_{i}^{*} *\left(\mathrm{a}_{\mathrm{i}} \lambda+\mathrm{b}_{\mathrm{i}} \beta+\mathrm{c}_{\mathrm{i}}\right)
$$

Where $\varphi=\left[a_{i}, b_{i}, c_{i}\right]$ are the consequent parameters to be optimally updated and $i=1,2$ are nodes in level 4 . The last level is non-adaptive solitary neurons which sum up every output of level 4 and converts the fuzzy outcomes into a crisp output. This is the optimized wind energy conversion coefficient which is the main focus of the study. That is at a specific input data-m ANFIS output is

$$
g^{m}=C_{p}=\sum_{i=1}^{R=2} a_{i}^{*} * g_{i}=\sum_{i=1}^{R=2} a_{i} * g_{i} / \sum_{i=1}^{R=2} a_{i}
$$

In ANFIS structure, the two-parameter sets to be updated are the predecessor parameters of input membership relations and resulting parameters of output membership relations. The ANFIS output $\left(g^{m=1}\right)$ is the linearly combined resulting parameters expressed as

$$
g^{1}=a_{1}^{*} * g_{1}+a_{2}^{*} * g_{2}
$$

Combining equations (12) and (14)

$$
g^{1}=\left(a_{1}^{*} \lambda\right) \mathrm{a}_{1}+\left(a_{1}^{*} \beta\right) \mathrm{b}_{1}+a_{1}^{*} \mathrm{c}_{1}+\left(a_{2}^{*} \lambda\right) \mathrm{a}_{2}+\left(a_{2}^{*} \beta\right) \mathrm{b}_{2}+a_{2}^{*} \mathrm{c}_{2}
$$

A hybrid back-spread learning technique of neural networks was used in ANFIS. ANFIS exploits learning capabilities with superior computation efficiency of neuron structures within a massively parallel application and fuzzy logics for expert knowledge depiction [27, 37, 38]. ANFIS uses a blended hybrid training to find the preceding parameters and the least square technique to get the consequent parameters. ANFIS optimizes premise parameters and they describe the form of the membership relation. The membership relations were adjusted to the input-output data at every level. Using this data, the FIS system and hybrid algorithm are used to tune the parameters of ANFIS. This intelligent system combines knowledge, technique, and methodology from sources of $\beta$ and $\lambda$ as per wind speed conditions. The membership functions know about a definite meadow-selves update and train to perform well in varying situations. Neural networks within ANFIS identify patterns and accelerate adjustment to various situations. As it was seen under levels 1 and 4, the premise and consequent parameters must be updated by the ANFIS training algorithm. That is the two vectors $\theta$ and $\varphi$ are optimally updated by the hybrid learning method. First, the premise parameters are fixed and in the forward path, the consequent parameters are trained by employing the least-squares learning technique using equation (15). Next, the already updated consequent parameters are fixed and in the backward path, the premise 
parameters are tuned using the gradient descent technique [39, 40].

In the ANFIS structure at level 4 , there are nodes $(i=1,2$ $=\mathrm{R}$ ), and the consequent parameters associated with the output of these nodes are $\varphi=\left[\partial_{1}, b_{1}, c_{1}, \partial_{2}, b_{2}, c_{2}\right]$. The output of ANFIS is a linear blend of products of the consequent parameters, normalized weights, and crisp inputs as seen in equation (15), and considering there are $\mathrm{m}=1,2 \ldots \mathrm{M}$ training data, the estimated output of ANFIS is

$$
O=\left[\begin{array}{c}
g^{1} \\
\vdots \\
g^{\mathrm{m}}
\end{array}\right]=\mathrm{A} \varphi
$$

The fuzzy membership premise parameters related to the normalized weights are maintained constant and hence matrix $\mathrm{A}$ is too; where

$$
\begin{aligned}
& A=\left[\begin{array}{cccccc}
\left(a_{1}^{*} \lambda\right)_{1} & \left(a_{2}^{*} \lambda\right)_{1} & \left(a_{1}^{*} \beta\right)_{1} & \left(a_{2}^{*} \beta\right)_{1} & \left(a_{1}^{*}\right)_{1} & \left(a_{2}^{*}\right)_{1} \\
: & : & : & : & : & : \\
\cdot & \cdot & \cdot & \cdot & \cdot & \cdot \\
\left(a_{1}^{*} \lambda\right)_{M} & \left(a_{1}^{*} \lambda\right)_{M} & \left(a_{1}^{*} \lambda\right)_{M} & \left(a_{1}^{*} \lambda\right)_{M} & \left(a_{1}^{*} \lambda\right)_{M} & \left(a_{1}^{*} \lambda\right)_{M}
\end{array}\right] \\
& \varphi=\left[\begin{array}{llllll}
a_{1} & a_{2} & b_{1} & b_{2} & c_{1} & c_{2}
\end{array}\right]^{T}
\end{aligned}
$$

The error between the desired and estimated output of ANFIS is

$$
\Xi=A \varphi-O
$$

To determine the optimal consequent parameters, define the cost function, and minimize it as in equations (19) and (20).

$$
\begin{aligned}
& \|\Xi\|^{2}=(A \varphi-O)^{T}(A \varphi-O) \\
& \frac{\partial\|\Xi\|^{2}}{\partial \varphi}=0, \text { and hence } \varphi=\left(A^{T} A\right)^{-1} A^{T} O
\end{aligned}
$$

The inverse of $\left(A^{T} A\right)$ must be non-singular, in case a sequential method can be used to compute the least square estimate of $\varphi$.

In this study, five MFs are used in fuzzification of each crisp inputs and each triangular $\mathrm{MF}$ has three premises parameters; thus, for two inputs 30 premises parameters are to be updated. But, once the parameters in the first MF of each input are optimally updated, it can be uniformly used for the remaining MFs. That is $\chi_{i 1}=\chi_{i 2}=. .=\chi_{i 5} ; \ldots ; q_{i 1}=q_{i 2}=\ldots q_{i 5}$ . The premises parameters $\theta=\left[\chi_{i j}, \delta_{i j}, \gamma_{i j}, p_{i j}, \xi_{i j}, q_{i j}\right]$ at level 1 of ANFIS is updated employing backpropagation of gradient descent. The network in Fig. 5 has five levels and $n$ $=1,2 \ldots \mathrm{N}(\mathrm{l})$ nodes in each level-1. The square of the norm of error of output at node-i in level-1 to training data $1 \leq m \leq$ $\mathrm{M}$ is defined as

$$
\|\varepsilon\|^{2}=\frac{1}{2} \sum_{n=1}^{N(l)}\left(o_{n}-g_{n}{ }^{l}\right)^{2}
$$

Any premise parameter is updated as

$$
\theta_{\text {new }}=\theta_{\text {old }}-\sigma \cdot \frac{\partial \varepsilon}{\partial g_{n}{ }^{l}} \frac{\partial g_{n}{ }^{l}}{\partial \theta}
$$

For fast convergence of training, at an initial iteration, the learning rate is $\sigma \leq 1$ and becomes 0 at the end of iteration [41]. Using the chain differential rule, the change in any premise parameter is carried as follows.

$$
\begin{aligned}
& \frac{\partial \varepsilon}{\partial g_{n}{ }^{l}}=-\sum_{n=1}^{N(t)}\left(o_{n}-g_{n}{ }^{l}\right)=-\varepsilon \\
& \frac{\partial g_{n}{ }^{l}}{\partial \theta}=\frac{\partial g_{i}{ }^{l}}{\partial a^{*}{ }_{i}} \frac{\partial a_{i}^{*}}{\partial a_{i}} \frac{\partial a_{i}}{\partial \mu_{i}} \frac{\partial \mu_{i}}{\partial \theta}
\end{aligned}
$$

Where $\mu_{i}$ stands for either $\mu_{\lambda_{i}}(\lambda)$ or $\mu_{\beta_{i}}(\beta)$ and for

$$
\frac{\partial \mu_{i}}{\partial \delta_{i j}}=\left\{\begin{array}{l}
\frac{\chi_{i j}-\lambda}{\left(\delta_{i j}-\chi_{i j}\right)^{2}} ; \lambda \leq \delta_{i j} \\
\frac{\gamma_{i j}-\lambda}{\left(\gamma_{i j}-\delta_{i j}\right)^{2}} ; \lambda \geq \delta_{i j}
\end{array} ; \frac{\partial \mu_{i}}{\partial \xi_{i j}}=\left\{\begin{array}{l}
\frac{p_{i j}-\beta}{\left(\xi_{i j}-p_{i j}\right)^{2}} ; \beta \leq \xi_{i j} \\
\frac{q_{i j}-\beta}{\left(q_{i j}-\xi_{i j}\right)^{2}} ; \beta \geq \xi_{i j}
\end{array}\right.\right.
$$

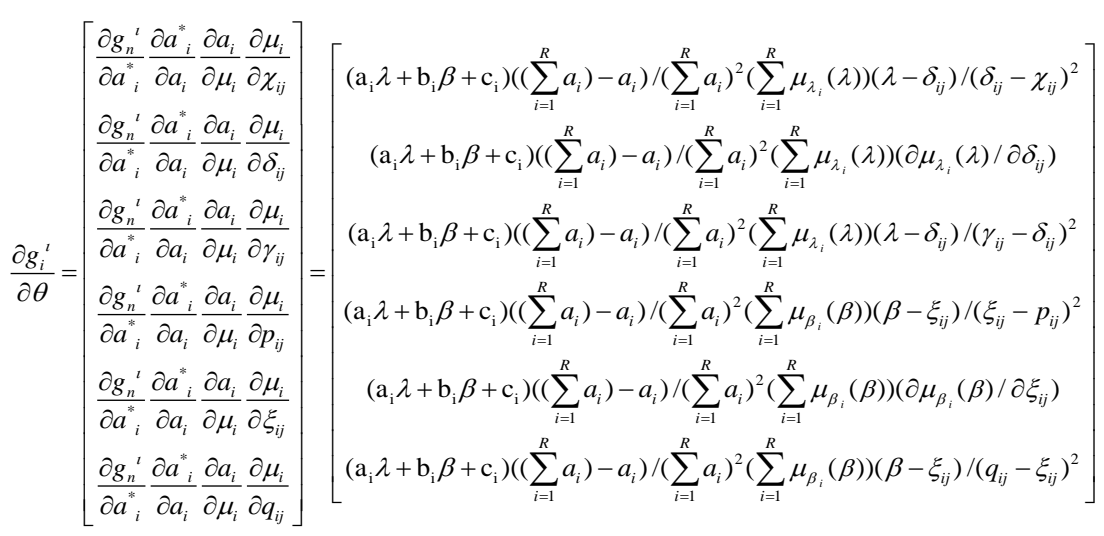

The training of ANFIS parameters was carried using the Matlab software. The hybrid learning technique for the ANFIS parameters was entrenched in Matlab's fuzzy inference toolbox. With the input data, this toolbox is used for the parameter training. Using the input wind speed data of Fig. 1, tip speed ratio $(\lambda)$, and pitch angle $(\beta), C_{p}$ optimization is done using ANFIS. About $75 \%$ of the data are used for training purposes by setting them for 100 iterations whereas the remaining $25 \%$ of data were for validation of the result. It has been well seen that the convergence is reached within very fewer epochs under the application of the hybrid learning technique for MFs parameters optimization. The ANFIS training Parameters are shown in Table I. Its network has five triangular shaped 
MFs for each input individually as seen in Fig. 6. As indicated in this figure, the tip speed ratio of value between 0-16 and the pitch angle of value between 0-20 degrees are used. At the beginning of training, the premise parameters are randomly assigned as seen in Fig. 7. That is for better accuracy considering $50 \%$ overlap of MFs, the initial premises are $\quad \chi_{i j}=0, \delta_{i j}=4, \gamma_{i j}=8 \quad$ and $p_{i j}=0, q_{i j}=5, \xi_{i j}=10$. The validation of the training result is evaluated by using the root mean squared error. The minimum training error of the membership function by the aforementioned method is 0.0013 as shown in Fig. 6.

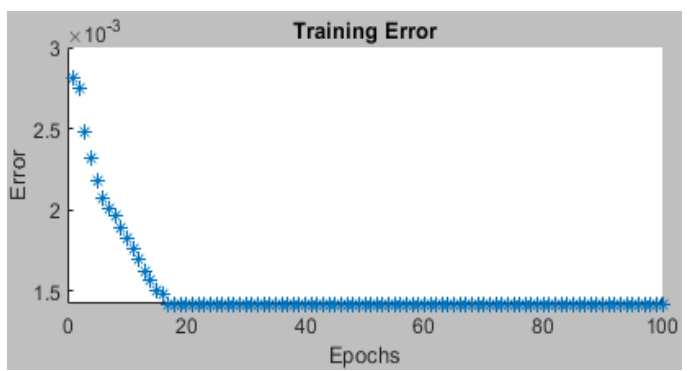

Fig. 6. Training error convergence using hybrid training

TABLE I. ANFIS SIMULATION SPESIFICATIONS

\begin{tabular}{|c|c|}
\hline Neurons & 75 \\
\hline Linear parameters & 75 \\
\hline Nonlinear parameters & 30 \\
\hline Entire parameters & 105 \\
\hline Data pairs training & 1000 \\
\hline FIS Train optimal method & Hybrid \\
\hline Checked data pairs & 250 \\
\hline Fuzzy rules & 25 \\
\hline
\end{tabular}

The pair of data inputs into the ANFIS structure for its parameters training and validation are generated considering the real wind speed data in Fig. 2, and equations (5a) and (5b) in combination with the specification of the Gamesa G80 wind turbine in Table III. At optimal values of $\lambda$ and $\beta, C_{p}$ can be optimized to capture optimal energy. The FIS rules are formulated using the analytical expression in Eq. (3) for the optimization of $\mathrm{C}_{\mathrm{p}}$ by ANFIS. It contains twenty-five "IF $\lambda$ is - and $\beta$ is THEN $C_{p}$ is -" fuzzy rules as shown in Table II and Fig. 9 for $\mathrm{ZE}=$ zero, $\mathrm{S}=$ small, $\mathrm{ME}=$ mean, $\mathrm{A}=$ average, $\mathrm{LA}=$ large, and VEL = very largely are linguistic variables.

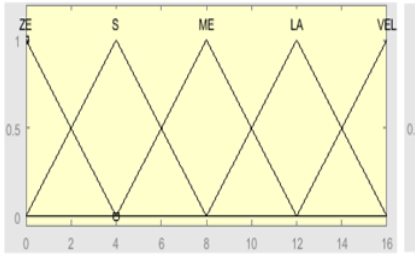

(a)

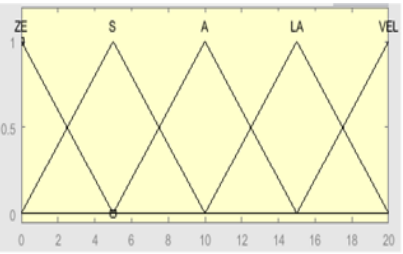

(b)
Fig. 7. Inputs membership function for (a) Tip ratio and (b) Blade pitch angle

TABLE II. ANFIS RULES FOR $\mathrm{C}_{\mathrm{P}}$ OPTIMIZATION

\begin{tabular}{|c|c|c|c|c|c|c|}
\hline \multicolumn{2}{|c|}{$\mathbf{C}_{\mathbf{p}}$} & \multicolumn{4}{c|}{$\mathbf{c}$} \\
\cline { 3 - 8 } & ZE & S & A & L & VL \\
\hline \multirow{4}{*}{$\lambda$} & ZE & ZE & ZE & ZE & ZE & ZE \\
\cline { 2 - 7 } & S & S & S & S & S & ZE \\
\cline { 2 - 7 } & ME & VL & LA & ME & S & ZE \\
\cline { 2 - 7 } & LA & S & S & S & S & ZE \\
\cline { 2 - 7 } & VEL & ZE & ZE & ZE & ZE & ZE \\
\hline
\end{tabular}

When the wind speed becomes more than the rated speed, the optimized power is greater than the rated power of the wind turbine generator unit. The generator output power should be regulated to the rated value. In parallel with optimization, this was achieved by controlling the variable pitch angle of the turbine blade actuator using a fuzzy logic controller. It generates a reference pitch angle $\left(\beta_{\text {ref }}\right)$. The model of the blade pitch actuator is presented in Fig. 8. This is one block element in Fig. 5. The limiter element in Figure 8 limits the rate of change of blade pitch angle between 5 and $10 \mathrm{deg} / \mathrm{sec}$ with the accuracy of the pitch actuator is between 0.25 and 3 degrees. Hence, the time constant ( $\tau=0.233 \mathrm{sec})$ of the pitch actuator is computed using the pitch actuator's rate of change of angle and accuracy. The saturation block keeps the pitch angle in the range of 0 to 90 degrees. The pitch angle controller was designed to have suitable values for the pitch angle input to power conversion coefficient optimization in the ANFIS scheme as shown in Fig. 5. The inputs of the fuzzy logicbased pitch angle controller are wind speed $\left(\mathrm{V}_{\mathrm{a}}\right)$ and the error $(\Delta \mathrm{P})$ between the generator's actual output power $\left(\mathrm{P}_{\mathrm{g}}\right)$ at any instant time and the reference power $\left(\mathrm{P}_{\text {ref }}\right) . \Delta \mathrm{P}$ was calculated as follows.

$$
\Delta \mathrm{P}=\mathrm{P}_{\mathrm{g}}-P_{\text {ref }}
$$

Linguistic variables of the input to the fuzzy logic controller are presented in Table III for NBIG, ZERO, PSMALL, PMID, PBIG, which are fuzzy subsets represent negative big, zero, positive small, positive medium, and positive big respectively. As depicted in Table III, twentyfive "IF $\Delta \mathrm{P}$ is - and $\mathrm{V}_{\mathrm{a}}$ is - THEN $\beta_{\text {ref }}$ is -" fuzzy logic rules are used and the command input to the blade actuator was generated. As an illustration, IF $\triangle \mathrm{P}$ is $\mathrm{NBIG}$ and $\mathrm{V}_{\mathrm{a}}$ is ZERO THEN $\beta_{\text {ref }}$ is NBIG. This means if the difference between the output power of the generator and reference power is negatively big and wind speed is zero then the rotor blade pitch angle will be necessarily reduced to optimize generator output power.

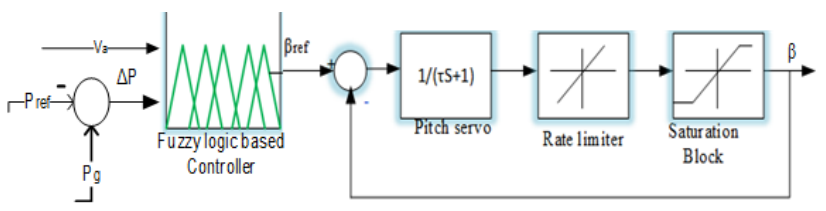

Fig. 8. Fuzzy logic controller wind turbine blade pitch actuator

TABLE III. FIS RULES FOR FUZZY LOGIC CONTROLLER OF THE PITCH ACTUATOR

\begin{tabular}{|c|c|c|c|c|c|}
\hline \multicolumn{2}{|c|}{$\mathbf{V}_{\mathbf{a}}$} & $\Delta \mathbf{P}$ & \multicolumn{3}{c|}{$\boldsymbol{\beta}_{\text {ref }}$} \\
\hline $\begin{array}{c}\text { Ranges } \\
(\mathbf{m} / \mathbf{s})\end{array}$ & $\begin{array}{c}\text { Ling. } \\
\text { Var. }\end{array}$ & $\begin{array}{c}\text { Ranges } \\
(\mathbf{M W})\end{array}$ & $\begin{array}{c}\text { Ling. } \\
\text { Var. }\end{array}$ & $\begin{array}{c}\text { Ranges } \\
(\mathbf{d e g})\end{array}$ & $\begin{array}{c}\text { Ling. } \\
\text { Var. }\end{array}$ \\
\hline$\left[\begin{array}{ll}0 & 3.5\end{array}\right]$ & Zero & {$[-2-1.93]$} & Nbig & {$[-200]$} & Nbig \\
\hline$\left[\begin{array}{lll}3.5 & 11\end{array}\right]$ & Small & {$[-1.930]$} & Zero & {$\left[\begin{array}{ll}0 & 1\end{array}\right]$} & Zero \\
\hline$\left[\begin{array}{lll}11 & 15\end{array}\right]$ & Mid & {$\left[\begin{array}{ll}0 & 0.5\end{array}\right]$} & Psmall & {$\left[\begin{array}{ll}1 & 8\end{array}\right]$} & Psmall \\
\hline$\left[\begin{array}{lll}15 & 20\end{array}\right]$ & Big & {$\left[\begin{array}{ll}0.5 & 1.2\end{array}\right]$} & Pmid & {$\left[\begin{array}{ll}8 & 14\end{array}\right]$} & Pmid \\
\hline$\left[\begin{array}{ll}20 & 25\end{array}\right]$ & Vbig & {$\left[\begin{array}{lll}1.2 & 2\end{array}\right]$} & Pbig & {$[1420]$} & Pbig \\
\hline
\end{tabular}

\section{RESULTS AND DISCUSSION}

Two-dimensional rule viewers for specified values of $\lambda$ and $\beta$ with corresponding $C_{p}$ are displayed in Fig. 9. This figure depicts the MFs of the fuzzy rules with the characteristic degree $(\mu)$ of each MF of all inputs and output variables. MFs are on the vertical axis; and the inputs and output variables are on the horizontal axis. For the wind speed below nominal speed, the best possible 
values for $\beta$ and $\lambda$ are searched by ANFIS iteratively and hence the corresponding $C_{p}$ becomes optimal. Using realtime wind speed data from Fig. 3 and after iterations are completed, the

ANFIS produced the best value of power conversion coefficient equal to 0.513 . This $\mathrm{C}_{\mathrm{p}}$ value is very promising and superior compared to its values available in the literature of related works $[9,16,18]$. At the obtained best value of $C_{p}$, the corresponding optimal values of $\lambda$ and $\beta$ are 8 and $0.636^{\circ}$ respectively. The optimal $C_{p}$ is used to optimize power when wind speed is below the rated value. In this study, variable pitch control is employed and hence the $\mathrm{C}_{\mathrm{p}}$ is tuned by ANFIS as the pitch angle adjusted by the pitch actuator control. That is, as the wind speed goes beyond its rated value the pitch angle is increased and thus $\mathrm{C}_{\mathrm{p}}$ is reduced and turbine output power is regulated to its rated value.

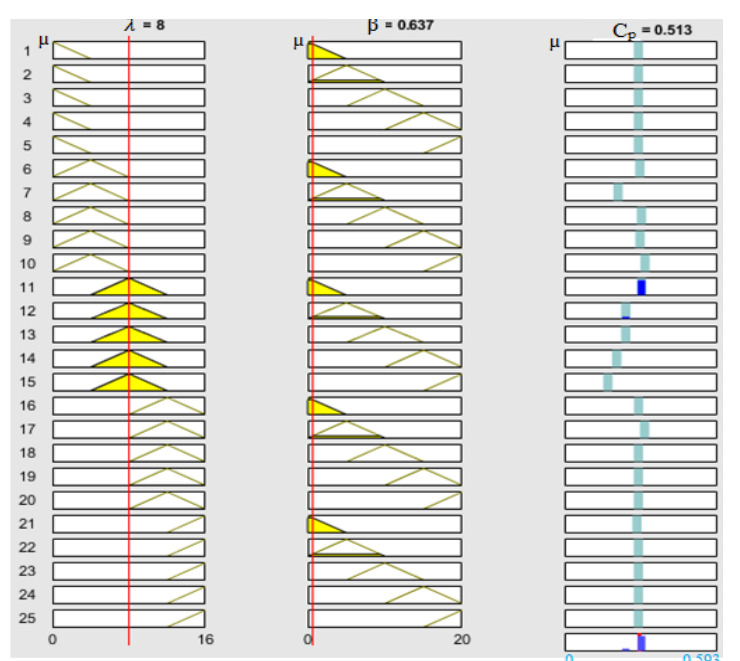

Fig. 9. Rule viewer for the twenty-five "IF $\lambda$ is - and $\beta$ is - THEN C $_{\mathrm{p}}$ is -" fuzzy rules in Optimizing $\mathrm{C}_{\mathrm{p}}$

For comparison of the improved power harvesting ability of wind turbines, power density versus wind speed for the selected Adama-II wind farm site is plotted in Fig. 10 for the various values of $C_{p}$ as discussed in section one referring to the works in different literature. This means, considering different optimal values for $\mathrm{C}_{\mathrm{p}}$ equal to 1 (total wind energy assumption), $\mathrm{C}_{\mathrm{p}}$ equal to 0.593 (Betz's limit), maximum $C_{p}$ value equals 0.467 for the Gamesa G80 wind turbine (which is extracted from the manufacturer power curve of this turbine [42]), the average value of $C_{p}$ equal to 0.353 (available in most literature like [13]), the maximum value $C_{p}$ equal to $0.472[9,16,18]$, and for $C_{p}$ equals 0.513 which is the result of this study.

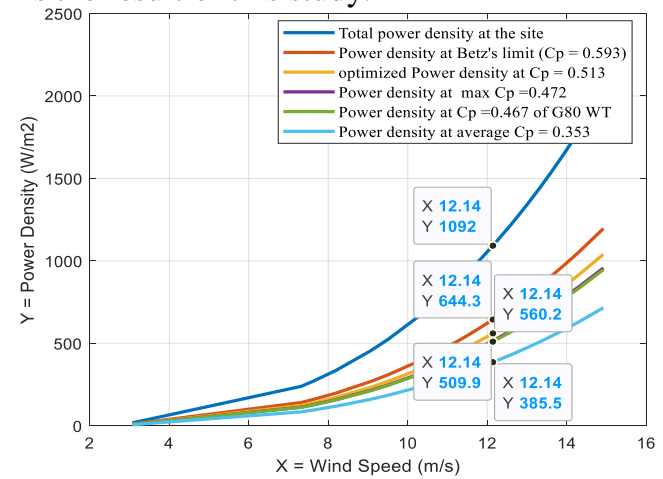

Fig. 10. Extractable power density for different values of $C_{p}$ using Adama wind farm site wind speed
The power density of any selected wind site should be assessed and plotted at the ideal conversion coefficient of energy since it is the performance of wind turbines. Fig. 10 shows the effect of various values of $\mathrm{C}_{\mathrm{p}}$ on energy harvesting. It is seen from Fig. 10 that the site has very good wind power potential. For the aforementioned specific values of $C_{p}$, multiplying the power density in Fig. 10 with the swept area of the Gamesa G80 wind turbine, the resulting output power is depicted as shown in Fig. 11 considering the extrapolated daily average wind speed data of January 2019 to the hub height of Gamesa G80 wind turbine. Also, the power produced by stand-alone Gamesa G80 wind turbine at 8.19 and $12.14 \mathrm{~m} / \mathrm{s}$ wind speeds and different values of $\mathrm{C}_{\mathrm{p}}$ are evaluated and tabulated in Table IV. According to the results in Table 4, it is observed that with adjustment in the tip speed ratio and the pitch angle, there is an improvement in the power conversion coefficient. This means, at the same wind speed, there is about $45.2 \%$ improvement in the power captured at $C_{p}$ equal to 0.513 as compared with power harvested at $C_{p}$ value of 0.353 . In other words, there is a $297 \mathrm{~kW}$ improvement in captured power at the wind speed of 8.19 $\mathrm{m} / \mathrm{s}$. Comparing the generator output power at the optimized $\mathrm{C}_{\mathrm{p}}$ and that captured at maximum $\mathrm{C}_{\mathrm{p}}$ of G80 $\left(\mathrm{C}_{\mathrm{p}-}\right.$ $\max$ is 0.467 ), the improvement of $76.21 \mathrm{~kW}$ at the wind speed of $8.19 \mathrm{~m} / \mathrm{s}$ and $194.3 \mathrm{~kW}$ when the wind speed is 12 $\mathrm{m} / \mathrm{s}$ are achieved. This is a $9.74 \%$ improvement in the harvested power. The optimized output power of the turbine equals the rated power at $11 \mathrm{~m} / \mathrm{s}$ wind speed. For wind speed greater than $11 \mathrm{~m} / \mathrm{s}$, it needs power regulation.

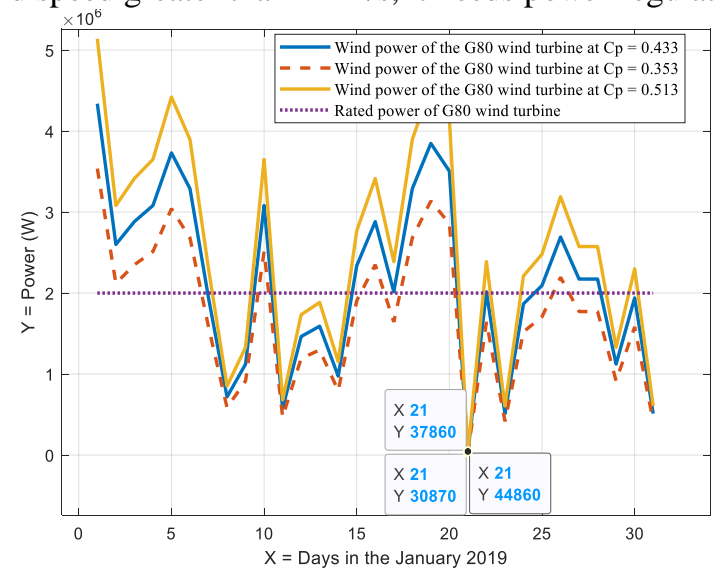

Fig. 11. Monthly harvestable unregulated power from the wind by Gamesa G80 at different calues of $\mathrm{C}_{\mathrm{p}}$

TABLE IV. COMPARISON OF SIMULATION RESUlTS OF POWER EXTRACTED BY GAMESA G80 WIND TURBINE FROM WIND AT DIFFERENT VALUES OF $\mathrm{C}_{\mathrm{P}}$

\begin{tabular}{|c|c|c|c|c|}
\hline \multicolumn{5}{|c|}{$\begin{array}{l}\text { At } 1.22 \mathrm{~kg} / \mathrm{m}^{3} \text { air density Power Harvested by G80 } 2 \mathrm{MW}, 67 \mathrm{~m} \\
\text { hub height, } 80 \mathrm{~m} \text { rotor diameter that has } 3.5,12 \text {, and } 25 \mathrm{~m} / \mathrm{s} \text { are } \\
\text { cut-in, nominal and cut-out wind speed respectively, and rotor } \\
\text { speed } 9-19 \mathrm{rpm} \text {, generator efficiency }\left(\eta_{\mathrm{g}}\right)=0.97 \text { and gearbox } \\
\text { efficiency }\left(\eta_{\mathrm{gb}}\right)=0.97\end{array}$} \\
\hline $\begin{array}{c}\text { Power conversion } \\
\text { coefficient }\left(\mathbf{C}_{p}\right)\end{array}$ & 0.513 & 0.472 & 0.467 & 0.353 \\
\hline Wind Speed (m/s) & \multicolumn{4}{|c|}{ Harvested Power $(\mathrm{kW})$} \\
\hline 8.19 & 965 & 797 & 884 & 595 \\
\hline 12 & 2584 & 2377 & 2352 & 1778 \\
\hline
\end{tabular}

As presented in section 2, when the wind speed is below cut-in speed, the turbine rotor is at a stall position and for the wind speed between cut-in and rated wind speeds, the blade pitch angle is zero to optimize power capturing. 
When the speed becomes more than the rated speed, the pitch angle was increased and hence rotor output power was regulated. That is, for wind speed above the nominal value, $\beta$ grows to regulate the output power of the rotor. At any wind speed, the corresponding value of the blade pitch angle is depicted in Fig. 12 and so that the turbine should limit the power or it should stall i.e. $\mathrm{C}_{\mathrm{p}}$ falls to zero.

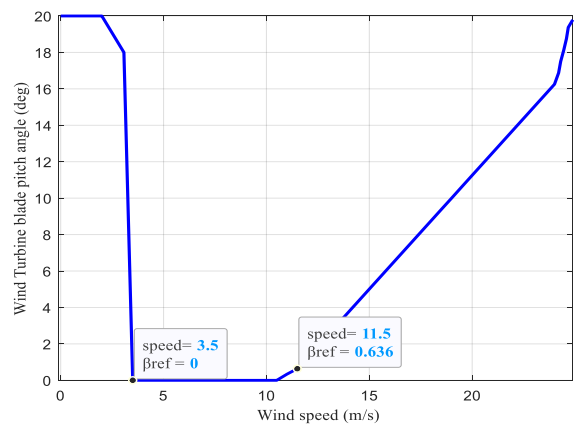

Fig. 12. Gamesa G80 wind turbine blade actuator input reference (command) angle

To illustrate graphically the improved and regulated output power of the G80 wind turbine by implementing intelligent soft computing, Fig. 13 is plotted for the regulated rotor output power of the G80 wind turbine. The considered wind speed is between the turbine cut-in and cut-out wind speeds. As indicated in the manufacture power curve [42] of G80, normally its rated power is attained at the wind speed larger than the nominal value (12 $\mathrm{m} / \mathrm{s}$ ). But the optimized power of the rotor output through $\mathrm{C}_{\mathrm{p}}$ optimizing is reached the rated value $(2 \mathrm{MW})$ at the wind speed of $12 \mathrm{~m} / \mathrm{s}$ whereas from the manufacturer power curve, it is $1.845 \mathrm{MW}$ at this wind speed.

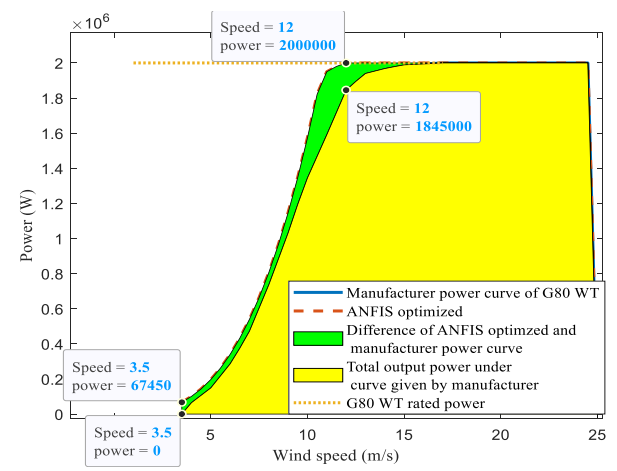

Fig. 13. Simulation of Gamesa G80 output power of wind speed between cut-in and cut-out vallues

This demonstrates the optimization technique employed in this study enables the wind turbine to harvest more power at lower wind speed. In short, the green color shaded area proves the enhanced power capturing ability of the wind turbine by the employed optimization technique. Here, the result is validated when compared to the results that were achieved by using a recent optimization technique in the literature. For instance, if the result in [43] with the optimal $\mathrm{C}_{\mathrm{p}}$ of 0.48 is taken as a benchmark, the minimum of $6.88 \%$ improvement in the energy capturing ability of wind turbines is reached. This work advances in power harvesting capacity of wind turbines. Even at low wind speed, the output power of the turbine for optimized $\mathrm{C}_{\mathrm{p}}$ is superior to the output power curve of the G80 wind turbine given by the manufacturer.

\section{CONCLUSIONS}

The paper presented the optimization of the power harvesting capacity of wind turbines using the real-time intelligent system. The wind data of a complete one-year of 2019 is collected from the Adama-II wind farm site and assessed. The wind data is input to a real-time intelligent soft computing system-ANFIS and the wind power conversion coefficient is optimized. Accordingly, it is well seen that the power capturing capacity of the wind turbine is improved with the resulted power conversion coefficient of 0.513 which is higher than the values depicted in the most recent works. Using this value of $C_{p}$ for the Gamesa G80 wind turbine generator, about $9.74 \%$ (e.g. $76.21 \mathrm{~kW}$ at $8.19 \mathrm{~m} / \mathrm{s}$ and $194.3 \mathrm{~kW}$ at $12 \mathrm{~m} / \mathrm{s}$ ) improvement in the harvested power is achieved. In comparison to related recent works presented in the literature, the power capturing capacity is improved by a minimum of $6.88 \%$. This study showed when the wind turbine operates in the wind with a speed below the nominal value, the turbine power capturing ability was improved by optimizing the power conversion coefficient and its output power was regulated when the wind speed was above the nominal value. This is archived by employing intelligent soft computing techniques.

\section{ACKNOWLEDGEMENTS}

This research is financed by the Centre of Excellency for Sustainable Energy, Addis Ababa Science and Technology University, Ethiopia. The research Code is AASTU/GP-F7C.

\section{REFERENCES}

[1] REN21 (2020) Renewable Energy Policy Network, "Renewables 2020 Global Status Report," https://www.ren21.net/gsr2020/chapters/chapter_03/chapter_03/. Accessed 22 June 2020

[2] M-H. Chiang, "A novel Pitch control system for a wind turbine driven by a variable-speed pump-controlled hydraulic servo system," Mechatronics 21: 753-761, 2011.

[3] S.M. Muyeen, A. Al-Durra, and J. Tamura, "Variable speed wind turbine generator system with current-controlled voltage source inverter," Energy Conversion and Management 52 (7): 2688-2694, 2011.

[4] L.M. Fernández, C.A. García, J.R. Saenz, F. Jurado, "Equivalent models of wind farms by using aggregated wind turbines and equivalent winds," Energy Conversion and Management 50 (3): 691-704, 2009

[5] E. Lindeberg, H. G Svendsenb, and K. Uhlenc, "Smooth transition between controllers for floating wind turbines," Energy Procedia 24: 83-98, 2012.

[6] Yushi Sachan, Akhilesh Kumar Gupta, Paulson Samuel, "A Review of MPPT Algorithms Employed in Wind Energy Conversion Systems," Journal of Green Engineering 6-4: 385-402, 2017.

[7] Soumia EL HANI, Said GUEDIRA, Noureddine EL ALAMI, "Maximum power tracking control wind turbine based on permanent magnet synchronous generator with complete converter," International Journal of Smart Grid and Clean Energy 3(1), 2014.

[8] Jogendra Singh Thongam, Mohand Ouhrouche, "MPPT Control Methods in Wind Energy Conversion Systems," Fundamental and Advanced Topics in Wind Power ISBN: 978-953-307-508-2: 339359, 2011.

[9] Dinh-Chung Phan, Shigeru Yamamoto, "Maximum Energy Output of a DFIG Wind Turbine Using an Improved MPPT-Curve Method," Energies 8: 11718-11736, 2015. DOI: 10.3390/en81011718

[10] Zongze Cui, Liwei Song, Shupe Li, "Maximum Power Point Tracking Strategy for a New Wind Power System and Its Design Details," IEEE Transactions on Energy Conversion 32(3): 1063 1071, 2017.

[11] Ofualagba, G., Ubeku, E. U., "Wind energy conversion systemwind turbine modeling," 2008 IEEE Power and Energy Society 
General Meeting - Conversion and Delivery of Electrical Energy in the 21stCentury 2008. https://doi:10.1109/pes.2008.4596699

[12] V. Kumar, R. R. Joshi, \& R. C. Bansal, "Optimal Control Matrix Converter based WECS for Performance Enhancement and Efficiency optimization," IEEE Transaction Energy Conversion 24(1): 264-273, 2009.

[13] D. Petkovic, Ž. Cojbašic, and V. Nikolic, "Adaptive neuro-fuzzy approach for wind turbine power coefficient estimation," Renewable and Sustainable Energy Reviews 28: 191-195, 2013.

[14] R. Sitharthan, T. Parthasarathy, S. Sheeba Rani, KC. Ramya, "An improved radial basis function neural network control strategybased maximum power point tracking controller for wind power generation system," Transactions of the Institute of Measurement and Control 41(22): 1-13, 2019.

[15] Saad, L., Hicham, H., \& Khalid, F., "Optimal tracking, modeling, and control of aerogenerator based on PMSG driven by a wind turbine," 2016.ICRERA. https:/doi:10.1109/icrera.2016.7884464

[16] Y. Soufi, S. Kahla and M. Bechouat, "Particle swarm optimizationbased sliding mode control of variable speed wind energy conversion system," International Journal of Hydrogen Energy 41: 20956-20963, 2016.

[17] A. Ghaffari, \& M. Krstic, "Power Optimization and Control in Wind Energy Conversion Systems Using Extremum Seeking," IEEE Transaction on Control Systems Technology 22(5): 1684-1695, 2014.

[18] Tony Hawkins, "Maximization of Power Capture in Wind Turbines using Robust Estimation and Lyapunov Extremum Seeking Control," Thesis, B.S., Kansas State University, 2010.

[19] Vaughn N, "Wind Energy Renewable Energy, and the Environment," 2nd edition. CRC Press Taylor \& Francis Group LLC, pp 115-129, 2014.

[20] M. Mohandes, S. Rehman, S.M. Rahman, "Estimation of wind speed profile using adaptive neuro-fuzzy inference system (ANFIS)," Applied Energy 88(11): 4024-4032, 2011.

[21] J.-S.R. Jang, "ANFIS: Adaptive-network-based fuzzy inference systems," IEEE Transactions on Systems Man and Cybernetics 23(3): 665-685, 1993.

[22] D. Petkovic, M. Issa, N. D. Pavlovic, N.T. Pavlovic and L. Zentner, "Adaptive neuro-fuzzy estimation of conductive silicone rubber mechanical properties," Expert Systems with Applications 39(10): 9477-9482, 2012.

[23] D. Petkovic, and Ž. Cojbašic, "Adaptive neuro-fuzzy estimation of automatic nervous system parameters effect on heart rate variability," Neural Computing, and Application 21(8): 2065-2070, 2012.

[24] S. Wua, Y. Wanga, S. Cheng, "Extreme learning machine based wind speed estimation and sensorless control for wind turbine power generation system," Neuro computing 102: 163-175, 2013.

[25] Y. Qi and Q. Meng, "The application of fuzzy PID control in a pitch wind turbine," Energy Procedia 16-part C: 1635-1641, 2012.

[26] Ahmadreza Abazari, Mehdi Ghazavi Dozen, Hassan Monsef An Optimal Fuzzy-logic Based Frequency Control Strategy in a High Wind Penetrated Power System. Journal of the Franklin Institute, 2018. DOI: 10.1016/j.jfranklin.2018.06.012.

[27] X. Jing, "Modeling, and control of a doubly-fed induction generator for wind turbine- generator systems," Thesis, Marquette University, 2012. http://epublications.marquette.edu/theses_open/167.

[28] Søren Gundtoft, "Wind Turbines," $2^{\text {nd }}$ Edition. University College of Aarhus, pp 7-8, 2009.

[29] Manwell, J F, McGowan, J G, Rogers, A L., "Wind Energy Explained: Theory, Design, and Application," John Wiley and Sons Ltd, pp $84-139,2002$.

[30] Electropaedia, "Battery, and Energy Technologies: Wind Power (Technology and Economics)," https://www.mpoweruk.com/wind_power.htm. Accessed 10 November 2020

[31] Ch S. Mathur S, "Modeling uncertainty analysis inflow and solute transport model using adaptive neuro-fuzzy inference system and particle swarm optimization," KSCE Journal of Civil Engineering 14(6): 941-951, 2010.

[32] Liu C., Liu X., Huang Hu, et al., "Low circle fatigue life model based on ANFIS. In: D. S. Huang, D. C. Wunsch II, D. S. Levine, et al. (eds) Advanced intelligent computing theories and applications: With aspects of contemporary intelligent computing techniques," Springer, Berlin, pp. 139-144. 2008.

[33] Tiwari M. K., Bajpai S., Dewangan U. K, "Prediction of industrial solid waste with ANFIS Model and its comparison with ANN Model - a case study of Durg-Bhilai Twin City India," International
Journal of Engineering and Innovative Technology 2(6): 192-201, 2012.

[34] Yetilmezsoy K., Fingas M., Fieldhouse B, "An adaptive neurofuzzy approach for modeling of water-in-oil emulsion formation," Colloids, and Surfaces A: Physicochemical and Engineering Aspects 389(1-3): 50-62, 2011.

[35] Giovanis E, "Study of discrete and adaptive neuro-fuzzy inference system in the prediction of economic crisis periods in the USA," Economic Analysis \& Policy 42(1): 79-95, 2012. http://dx.doi.org/10.1016/S0313-5926(12)50006-8

[36] Noori R., Abdoli M. A., Farokhnia A., et al., "Result: uncertainty of solid waste generation forecasting by a hybrid of wavelet transformANFIS and wavelet transform-neural network," Expert Systems

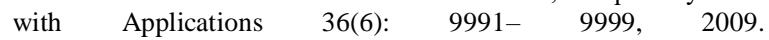
http://dx.doi.org/10.1016/j.eswa.2008.12.035

[37] M. A. Akcayol, "Application of adaptive neuro-fuzzy controller for SRM," Advances in Engineering Software 35(3-4) 129-137, 2004.

[38] A. Khajeh, H. Modarress, and B. Rezaee, "Application of adaptive neuro-fuzzy inference system for solubility prediction of carbon dioxide in polymers," Expert Systems with Applications 36(3) part 1: 5728-5732, 2009.

[39] Jang J.S. R, “ANFIS-Adaptive network-based fuzzy inference system," IEEE Transactions Systems, Man and Cybernetics 23(3): 665-685. http://dx.doi.org/10.1109/21.256541, 1993.

[40] Sara A. Van De Geer, "Encyclopaedia of Statistics in Behavioural Science," John Wiley \& Sons, Ltd, Chichester 2: 1041-1045, ISBN13: 978-0-470-86080-9ISBN-10: 0-470-86080-4, 2005.

[41] Jason Brownlee, "Machine Learning Mastery: Understand the Impact of Learning Rate on Neural Network Performance," https://machinelearningmastery.com. Accessed 10 November 2020.

[42] Gamesa G80, https://en.wind-turbine-models.com/turbines/34gamesa-g80, data modified on 03/07/2017.

[43] Abdel-Raheem Youssef, Mahmoud A. Sayed, M.N Abdel-Wahab, Gaber Shabib Salman, "Maximum Power Point Tracking of a Wind Power System Based on Five Phase PMSG Using Optimum Torque Control,” MEPCON'15, 2015. 